AperTO - Archivio Istituzionale Open Access dell'Università di Torino

\title{
CD157: From immunoregulatory protein to potential therapeutic target
}

\section{This is the author's manuscript}

Original Citation:

\section{Availability:}

This version is available http://hdl.handle.net/2318/1695398

since 2020-10-15T10:15:15Z

Published version:

DOI:10.1016/j.imlet.2018.06.007

Terms of use:

Open Access

Anyone can freely access the full text of works made available as "Open Access". Works made available under a Creative Commons license can be used according to the terms and conditions of said license. Use of all other works requires consent of the right holder (author or publisher) if not exempted from copyright protection by the applicable law. 


\title{
Manuscript Details
}

\section{Manuscript number}

Title

Article type
IMLET_2018_170

CD157: from immunoregulatory protein to potential therapeutic target

Review Article

\begin{abstract}
CD157/BST1 glycosylphosphatidylinositol-anchored glycoprotein is an evolutionary conserved dual-function receptor and $\beta$-NAD+-metabolizing ectoenzyme of the ADP-ribosyl cyclases gene family. Identified as bone marrow stromal cell and myeloid cell differentiation antigen, CD157 turned out to have a wider expression than originally assumed. The functional significance of human CD157 as an enzyme remains unclear, while it was well established in mouse models. Conversely, the receptor role of CD157 has been clearly delineated. In physiological conditions, CD157 is a key player in regulating leukocyte adhesion, migration and diapedesis. Underlying these functional roles is the ability of CD157 to bind with high affinity selected extracellular matrix components within their heparin-binding domains. CD157 binding to extracellular matrix promotes its interaction with $\beta 1$ and $\beta 2$-integrins and induces the organization of a multimolecular complex that is instrumental to the delivery of synergistic outside-in signals leading to optimal cell adhesion and migration, both in physiological and in pathological situations. CD157 also regulates cell adhesion and migration and is a marker of adverse prognosis in epithelial ovarian cancer and pleural mesothelioma. This review focuses on human CD157 expression and functions and provides an overview on its role in human pathology and its emerging potential as target for antibody-mediated immunotherapy.
\end{abstract}

\section{Keywords}

Taxonomy

Corresponding Author

Corresponding Author's Institution

Order of Authors
CD157/BST1; CD157 ligand; leukocyte trafficking; cell adhesion; myeloid cells, acute myeloid leukemia

Adhesion Molecule, Signal Transduction, Migration

ada funaro

University of Torino

Erika Ortolan, Stefania Augeri, Giulia Fissolo, Irene Musso, ada funaro

\section{Submission Files Included in this PDF}

\section{File Name [File Type]}

Cover letter.pdf [Cover Letter]

Highlights.docx [Highlights]

Manuscript.docx [Manuscript File]

Figure 1.eps [Figure]

Figure 2.eps [Figure]

To view all the submission files, including those not included in the PDF, click on the manuscript title on your EVISE Homepage, then click 'Download zip file'. 
Vito Pistoia

Editor-in-Chief

Immunology Letters

2018-04-18

Dear Editor:

I am pleased to submit the review article entitled "CD157: from immunoregulatory protein to potential therapeutic target” by Erika Ortolan, Stefania Augeri, Giulia Fissolo, Irene Musso and Ada Funaro, which we would like to submit for publication in the Special Issue of Immunology Letters dedicated to the immune side of ectoenzymes.

In this review article we provided an overview on human CD157/BST1 expression and functions in normal and pathological conditions and its recently emerging potential as target for antibody-mediated immunotherapy in acute myeloid leukemia.

On behalf of all the authors, I would like to thank you for the opportunity to contribute to this special issue of Immunology Letters.

I confirm that all authors have directly participated in the preparation of the manuscript and reviewed the final version and have agreed with the submission in its present form.

We hope that our review article will fit the scientific standards of Immunology Letters and we look forward to receiving your evaluation.

Sincerely yours,

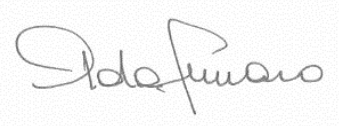

Ada Funaro

(Associate Professor of

Medical Genetics) 


\section{Highlights}

- $\mathrm{CD} 157$ is a dual-function receptor and $\beta-\mathrm{NAD}+$-metabolizing ectoenzyme

- CD157 regulates leukocyte trafficking

- CD157 plays a role in inflammation and in selected tumors

- CD157 is a promising target for antibody-mediated immunotherapy in acute myeloid leukemia 
CD157: from immunoregulatory protein to potential therapeutic target

Erika Ortolan ${ }^{\mathrm{a}}$, Stefania Augeria, Giulia Fissolo ${ }^{\mathrm{a}}$, Irene Musso ${ }^{\mathrm{a}}$ and Ada Funaro ${ }^{\mathrm{a} *}$

aLaboratory of Immunogenetics, Department of Medical Sciences, University of Torino, Via Santena 19, 10126 Torino, Italy

\section{*Corresponding author:}

Ada Funaro

Laboratory of Immunogenetics

Department of Medical Sciences

University of Torino

Via Santena, 19

10126 Torino, Italy

Phone: $(+39)$ 011-670-5991

Fax: (+39) 011-696-6155

E.mail: ada.funaro@unito.it 


\begin{abstract}
CD157/BST1 glycosylphosphatidylinositol-anchored glycoprotein is an evolutionary conserved dual-function receptor and $\beta$-NAD+-metabolizing ectoenzyme of the ADP-ribosyl cyclases gene family. Identified as bone marrow stromal cell and myeloid cell differentiation antigen, CD157 turned out to have a wider expression than originally assumed. The functional significance of human CD157 as an enzyme remains unclear, while it was well established in mouse models. Conversely, the receptor role of CD157 has been clearly delineated. In physiological conditions, CD157 is a key player in regulating leukocyte adhesion, migration and diapedesis. Underlying these functional roles is the ability of CD157 to bind with high affinity selected extracellular matrix components within their heparin-binding domains. CD157 binding to extracellular matrix promotes its interaction with $\beta 1$ and $\beta 2$-integrins and induces the organization of a multimolecular complex that is instrumental to the delivery of synergistic outside-in signals leading to optimal cell adhesion and migration, both in physiological and in pathological situations. CD157 also regulates cell adhesion and migration and is a marker of adverse prognosis in epithelial ovarian cancer and pleural mesothelioma.

This review focuses on human CD157 expression and functions and provides an overview on its role in human pathology and its emerging potential as target for antibody-mediated immunotherapy.
\end{abstract}

Key words: CD157/BST1, CD157 ligand, leukocyte trafficking, cell adhesion, innate immunity 


\section{Introduction}

CD157 has been discovered in 1985 as the Mo5 human myelomonocytic differentiation antigen [1]. A decade later, CD157 was identified and characterised as a cell surface receptor expressed in bone marrow stromal cells where it supports the growth of hematopoietic B cell progenitors, hence the name bone marrow stromal cell antigen 1 (BST1)[2] [3]. Subsequently, the Human Cell Differentiation Molecules organization (HCDM; www.hcdm.org) grouped together Mo5 and BST1 as CD157 cell differentiation marker. Human CD157 is a glycosylphosphatidylinositol (GPI)anchored glycoprotein conserved among vertebrates, that along with its paralogue $C D 38$, constitutes the ADP-ribosyl cyclases (ARC) gene family [4]. CD157 and CD38 genes maps to human chromosome $4(4 \mathrm{p} 15.33)$ and they show highly conserved exon structure and gene regulatory elements [5]. Until recently, only one BST1 gene consisting of nine exons and eight introns was known, which encodes the canonical CD157/BST1 protein of 318 amino acids [4]. Recently, our group discovered a second $B S T 1$ transcript, which encompasses an additional exon, located between exons 1 and 2 of the canonical BST1 gene, and encodes a novel CD157 proteoform (namely, CD157002) of 333 amino acids. This unexpected finding unveiled that canonical CD157 does not derive by constitutive splicing of the 9-exon BST1 gene as believed, but is generated by exclusion of the additional exon by alternative splicing [6]. So far, human CD157 is the first member of the ARC family to be described as being regulated by alternative splicing.

Several single-nucleotide polymorphisms (SNPs) at BST1 gene have been described, four of which (i.e., rs11931532, rs12645693, rs4698412 and rs4538475) were identified as risk factors in sporadic late-onset Parkinson disease in a Japanese GWA study, with rs4538475 showing the strongest association [7]. This association was confirmed in the northern Han Chinese population [8], while it was controversial in the European population $[9,10]$. Moreover, rs4301112 and rs28532698 SNPs at BST1 gene proved to be significantly associated with Autism spectrum disorders in a Japanese population [11] but not in a Han Chinese population [12], suggesting that the association between 
BST1 locus and sporadic late-onset Parkinson's disease or Autism spectrum disorders varies with ethnicity.

CD157 protein has a molecular weight ranging between $42-50 \mathrm{kDa}$ due to its heterogeneous glycosylation patterns [13]. CD157 exists both as membrane-bound and as a soluble protein that is measurable in sera [14] and in pleural and peritoneal effusions [15].

Human CD157 is prevalently expressed in cells belonging to the myelomonocytic lineage, especially in monocytes, neutrophils and more immature myeloid stages [16], hence its original designation as myeloid differentiation antigen. However, CD157 has a wider expression than previously thought; indeed, it was also found in vascular endothelium [17] and tissue-resident vascular endothelial stem cells [18], mesothelial cells [19], mesenchymal stem cells [20], follicular dendritic cells [21] and Paneth cells [22], and in many other cell types [23-31]. However, functional implications of CD157 in many of these tissues have not been fully examined. Over the past decade, we have found CD157 expression in epithelial ovarian cancer [32] and malignant pleural mesothelioma (MPM) [33], and in both tumor types a correlation emerged between CD157 expression levels and tumor aggressiveness. The expression of CD157 in lymphoid and non-lymphoid tissues is summarized in Table 1.

\section{CD157 enzymatic functions}

CD157 shares with CD38 the ability to convert $\beta$-NAD+ to cyclic ADP ribose (cADPR, minor product) and ADP ribose (APDR, major product), indicating the presence of ADP-ribosyl cyclase, NAD glycohydrolase and possibly cyclic adenosine 5'-diphosphoribose hydrolase activities [34, 35]. However, human CD157 ADP-ribosyl cyclase activity is hundreds fold less efficient compared to that of human $\mathrm{CD} 38$, requires an acidic $\mathrm{pH}(4.0-6.5)$ and the presence of metal $\left(\mathrm{Zn}^{2+}\right.$ and $\left.\mathrm{Mg}^{2+}\right)$ ions $[34,35]$. Actually, CD157 quantitative contribution to generate the intracellular second messenger cADPR by $\beta-\mathrm{NAD}+$ conversion is unknown. In contrast, the $\beta$-NAD + glycohydrolase activity of CD157 is readily detectable and leads to production of ADPR, which can act both as a substrate and 
as a second messenger [36]. Although CD157-002 shares similar distribution and receptor functions with canonical CD157, it does not display measurable NADase activity [6].

In contrast to what has been observed in human models, in murine models there is evidence that cADPR generation by CD157 may be biologically relevant in mediating paracrine signaling in hematopoiesis [37], in gut stem cell homeostasis in response to calorie restriction [22] and in social behavior, envisaging a role for CD157 as a neuro-entero-immune regulator [38].

\section{CD157 receptor functions}

First evidence of the receptor nature of CD157 was inferred from the observation that the protein expressed by bone marrow stromal cells supported the growth of a pre-B cell line [3]. Subsequently, several experimental evidence confirmed that CD157 behaves as a receptor capable of transducing intracellular signals. The receptor functions of CD157 were established long before the discovery of its physiological non-substrate ligand, thanks to the availability of specific agonistic (or blocking) monoclonal antibodies (mAb). Indeed, binding of CD157 with agonistic antibodies in several myelomonocytic cell line models induced tyrosine phosphorylation of a $130 \mathrm{kDa}$ protein, identified as focal adhesion kinase (FAK) [39], regulated calcium homeostasis and promoted polarization in neutrophils [40], and mediated superoxide (O2-) production in the U937 human myelomonocytic leukemia cells [41]. As CD157 lacks intracellular domains, it is unfit to transduce signals by its own. To overcame this intrinsic structural limitation, CD157 exploits the lateral mobility provided by the GPI-moiety to establish structural and functional interactions with co-receptors in the plasma membrane. In particular, in human leukocytes (neutrophils and monocytes), CD157 associates with CD29 ( $\beta 1$ integrin) and CD18 ( $\beta 2$ integrin) to form a multimolecular complex mediating out-side-in signal transduction [42].

As many other GPI-anchored proteins, CD157 is sorted into specialised cholesterol- and ganglioside-enriched microdomains in the cell membrane, referred to as lipid rafts. These membrane 
domains are dynamic assemblies of proteins and lipids that harbour many receptors and intracellular effectors and so act as platforms for signal transduction [43]. Upon binding to its ligand (or engagement by a specific mAb as a surrogate for the ligand), CD157 promotes the recruitment of $\beta 1$ and $\beta 2$ integrin into lipid rafts, thus inducing the formation of a multimolecular complex that delivers efficient downstream signals. In leukocytes, CD157-mediated intracellular signals relies on the integrin/FAK/Src pathway, leading to increased phosphorylation of tyrosine kinase receptors and activation of downstream MAPK/ERK1/2 and PI3K/Akt signaling pathways [44] (Figure 1).

\section{CD157 and its natural ligands}

Although it was clear since its discovery that CD157 induces a variety of cellular responses in leukocytes and other cell types, apparently unrelated from its enzymatic functions [40], for a long time, the efforts to define the non-enzymatic functions of CD157 have been hindered by the lack of a known biological ligand. The identification of the role of CD157 in leukocyte adhesion, migration and invasion and its functional and structural partnership with $\beta 1$ and $\beta 2$ integrins $[42,45]$, paved the way to discover the ability of CD157 to bind with high affinity to selected components of the extracellular matrix (ECM) such as fibronectin, fibrinogen, laminin-1 and type 1 collagen (but not vitronectin), within their heparin-binding domains [46]. The strong CD157/ECM interaction is instrumental to establish a physical interaction with integrins and to deliver intracellular signals regulating cell adhesion and migration. Consistently, knockdown of CD157 in myeloid, mesothelial or epithelial cells remarkably reduces fibronectin-mediated phosphorylation of FAK, Src, and Akt tyrosine kinases [46] and eventually affects cell adhesion and spreading [33, 47]. Overall, experimental evidence suggests that binding of human CD157 to selected ECM proteins mediates many of the biological effects exerted by CD157 in different physiological (e.g., leukocyte trafficking) and pathological contexts (e.g., inflammatory diseases and cancer), where the composition of the extracellular matrix in the local environment dictates the proper outcome. For 
example, in ovarian cancer, the CD157-ECM interaction occurring in the peritoneal cavity rescues floating tumor cells from anoikis and promotes their migration and metastatic dissemination, ultimately exacerbating tumor aggressiveness [47].

In human mesenchymal stem cells (MSC) CD157 in combination with integrin $\beta 1$ has been reported to act as a receptor for SCRG1 (scrapie responsive gene 1). SCRG1 is a soluble protein induced in transmissible spongiform encephalopathies and brain injuries, involved in the regulation of MSC self-renewal, migration, and osteogenic differentiation, especially in the central nervous system of mice infected with scrapie, where SCRG1 is highly expressed. The SCRG1/BST1/integrin axis maintains MSC self-renewal and multipotency and promotes the migration of human bone marrow-derived MSC through the activation of the FAK/PI3K/Akt signaling pathway [20]. However, functional significance of this interaction in vivo is currently unknown.

\section{Role of CD157 in immune response and inflammation}

In the mouse model, ample evidence demonstrated that CD157 is an immunoregulatory molecule implicated in early B and T cell growth and development [48]. Moreover, the expression of CD157 by murine $\mathrm{B}$ and $\mathrm{T}$ cell progenitors parallels rearrangement of antigen receptor genes [49]. In pro-B cells, BST1 is reported as PAX5-activated gene, adding supportive evidence that CD157 functions during rearrangement of antigen receptor genes [50]. The murine CD157 KO model highlighted that CD157 plays a role in the regulation of the humoral T-independent immune responses and the mucosal thymus-dependent response [51].

Our group has spent several years assessing the role of human CD157 in the innate and adaptive immune response, coming to the conclusion that CD157 has a key role in the control of myeloid cell migration and diapedesis during inflammation, a function which is fully consistent with its expression on leukocytes membrane and at intercellular border of vascular endothelial cells, and with its role as an adhesion molecule. In the early 2000s, using CD157-specific agonistic (or blocking) mAb, we 
demonstrated that CD157 regulates neutrophil and monocyte adhesion to ECM proteins and orchestrates their motility and transendothelial migration by establishing a structural and functional cross-talk with $\beta 1$ - [45] and $\beta 2$-integrin [40]. These findings were strengthened by the observation that neutrophils obtained from patients with paroxysmal nocturnal hemoglobinuria, an acquired genetic disease characterized by lack of GPI-anchored molecules, including CD157 [52], are characterized by severe defects in neutrophil adhesion, migration and transendothelial migration [17]. Hence, blocking CD157 with specific antibodies or its genetic loss, results in impaired cell adhesion to ECM proteins and reduced cell motility.

The discovery that CD157 binds with high affinity to the heparin-binding domains of fibronectin or other components of the ECM, revealed the nature of the physiological interaction(s) implementing multiple biological activities attributed to CD157 in normal and pathological conditions, unrelated to its role as enzyme $[32,33,46]$.

\section{CD157 in pathological conditions}

\subsection{Autoimmune diseases}

\subsubsection{Rheumatoid arthritis}

Several evidence showed that abnormal functions of the bone marrow (BM) play critical roles in the pathophysiology of rheumatoid arthritis (RA). Since RA-derived stromal cells express higher levels of CD157 than those derived from healthy subjects, it has been hypothesized that CD157 expressed by synovia-derived stromal cells may contribute to the pathogenesis of the disease by increasing the proliferative capacity and reducing apoptosis of pre-B cells [53, 54]. Moreover, soluble CD157 concentration in serum from patients with RA proved to be significantly higher than those from healthy subjects and to correlate with the severity of the disease [14], hinting to an involvement of CD157 in the progression of the disease. However, the mechanistic implication of CD157 in the pathophysiology of RA has never been substantiated by experimental evidence. 


\subsection{Hematologic malignancies}

\subsubsection{B-cell precursors acute lymphoblastic leukemia}

CD157 has been proposed as marker for disease monitoring in B-cell precursor acute lymphoblastic leukemia. Indeed, high CD157 expression discriminates malignant cells from CD157-negative normal B cells in the bone marrow from the same patient, and may be useful as an additional marker to detect and quantify residual leukemia cells at early treatment time points and during follow-up $[55]$.

\subsubsection{Acute myeloid leukemia}

Acute myeloid leukemia (AML), the most-common acute leukemia in adults, is a heterogeneous disease frequently associated with poor prognosis. Standard chemotherapies can induce complete remission in selected patients, however, most patients eventually relapse and succumb to the disease. Thus, the development of novel therapies for AML is an urgent need. The therapeutic armamentarium for AML has remained unchanged for decades, until the last two years, when multiple drugs with novel mechanisms of action and low toxicity have been approved [56]. Other agents are being tested in the clinic, especially immunotherapeutics, including monoclonal antibodies, chimeric antigen receptor-engineered T cells (CART cells), and checkpoint inhibitors [57].

CD157 is expressed in 97\% of AML patients both at time of primary diagnosis and relapse, regardless of the genetic profile. Notably, the highest expression of CD157 is associated to M4 and M5 subtypes [58], which represent the group in which conventional chemotherapy has limited efficacy. Albeit at lower extent, CD157 was also found in the compartment of leukemia-initiating cells, which are believed to be implicated in leukemia relapse [59]. These findings make CD157 an attractive target for immunotherapy in AML. To this aim, a novel anti-CD157 monoclonal antibody (MEN1112) has been developed by the Menarini Group (Pomezia, Italy) in collaboration with OBT (Oxford Bio Therapeutics, Oxon, UK). MEN1112 is a humanized de-fucosylated monoclonal IgG1, which binds 
to the Fc $\gamma$ receptor (CD16) on natural killer (NK) cells with enhanced affinity and exerts a robust anti-leukemia activity through antibody dependent cell-mediated cytotoxicty (ADCC) [59]. A phase I clinical trial is ongoing (NCT02353143).

Results from various studies convincingly established that the bone marrow (BM) microenvironment plays an important role in therapy escape of leukemic cells and occurrence of leukemic relapse [60]. Development of novel treatments targeting the cellular and molecular mechanisms that control dynamic AML-niche interactions represents an appealing strategy to overcome the limitations associated with intrinsic genetic heterogeneity of AML, and to resolve niche-mediated drug resistance. By virtue of its expression both by tumor cells and surrounding BM stromal cells (BMSC), it is reasonable to predict that CD157 takes part to a positive feedback loop in the interactions between AML cells and the BM microenvironment that feeds a 'vicious cycle' resulting in tumor cell protection from chemotherapy (Figure 2). Our preliminary results obtained in vitro from co-culture studies indicated that CD157 expressed by BMSC is involved in the protection of primary leukemic cells from the cytotoxic effect of cytosine arabinoside (AraC) treatment (EO and SA, personal observation) strengthening the potential clinical utility of CD157 as double therapeutic target acting both on leukemia cells and BM niche.

\subsection{Solid tumors}

\subsubsection{Ovarian cancer}

The expression of CD157 in mesothelial cells [19] on the one hand, and its involvement in the control of leukocyte trafficking, on the other, led us to assume that CD157 could be expressed by epithelial ovarian cancer cells and could be involved in the control of ovarian cancer dissemination. This hypothesis was independently supported by the identification of CD157/BST1 among genes overexpressed in primary cultures of epithelial ovarian cancer cells, compared to non-malignant epithelial cells [61]. Collectively, our experimental and clinical data demonstrated that CD157 is 
expressed by more than $90 \%$ of epithelial ovarian cancers and is an independent prognostic factor of tumor relapse shortly after surgery. In addition, CD157 is involved in the interactions between epithelial ovarian cancer cells, ECM proteins and peritoneal mesothelial cells, and through these functions it controls tumor cell migration and invasion into surrounding tissues. At the molecular level, the functional contribution of CD157 to the progression of epithelial ovarian cancer relies on its ability to switch on a differentiation program, which allows neoplastic cells to modulate selected genes. This eventually translates into increased expression of protein favoring tumor progression and reduced expression of proteins hindering tumor progression, which confers cells a highly malignant phenotype, and bring them toward the acquisition of morphological and functional features of mesenchymal cells, a prerequisite for cancer cell invasion and metastatic dissemination [47].

\subsubsection{Malignant Mesothelioma}

CD157 is also expressed in $>85 \%$ of MPM, which share embryonic origin, biologic and phenotypic properties and dissemination modalities of epithelial ovarian cancer. Again, high CD157 expression proved to be associated with enhanced tumor aggressiveness and shorter survival, notably in patients with MPM of biphasic histotype. In vitro, CD157 expression correlates with enhanced cell growth, migration, invasion and increased activation of the PI3K/Akt/mTOR pathway and reduced sensitivity to platinum-based chemotherapy. These findings are supported by clinical data indicating that patients with biphasic MPM and high CD157 expression that received platinum-based therapy had significantly shorter survival compared to patients with low CD157 expression [33]. Collectively, these data suggest that CD157 has potential clinical utility as a marker for stratifying patients with MPM into different prognostic groups. Moreover, CD157 may identify patients with highly aggressive MPM, which might benefit from a particular chemotherapeutic approach that may include specific inhibitors of the PI3K/Akt/mTOR pathway. Recent results from our group demonstrated that soluble CD157 levels is significantly higher in MPM effusions than in all other pleural effusions, both non-MPM malignant and non-malignant. Although sCD157 does not have the required accuracy 
for diagnostic purposes by its own, measurement of effusion sCD157 can provide supporting evidence for diagnosing MPM in symptomatic individuals when cytology is inconclusive [15].

\section{Conclusion}

CD157 identified over three decades ago as myeloid differentiation marker, has turned out to be a key player in the regulation and modulation of various aspect of leukocyte physiology and behavior of selected cancer types, hinting to potential clinical applications. Indeed, it is reasonable to envision that hindering the interaction between CD157 and fibronectin (or other ECM proteins, depending on each specific microenvironment) may represent a new avenue for the design of therapeutic approaches against chronic inflammation and cancer. For example, in chronic inflammatory conditions, such as arthritis and atherosclerosis, CD157 due to its structural and functional partnership with integrins, offers the opportunity for fine-tuning integrin functions avoiding to interfere directly with them. Integrins have been a focus of extensive and continuing research as therapeutic targets, but despite some outstanding therapeutic successes, the complexity of their function has often made treatment development challenging, especially in cancer therapy [62]. Regardless of the encouraging in vitro and preclinical results, late phase clinical trials have, thus far, been disappointing. It is possible that targeting proteins interacting with integrins, rather than integrins themselves, would be a more beneficial therapeutic approach. In ovarian cancer and mesothelioma patients, it is tempting to predict that $\mathrm{CD} 157$ can be useful as novel marker to formulate prognostic stratification and to refine therapeutic selection of patients, and possibly, as novel therapeutic target to counteract invasion and dissemination of cancer cells. 
8. Acknowledgements: This work was supported by grants from the Italian Association for Cancer Research (AIRC, IG. 15968 to A.F.), from the Italian Ministry for University and Scientific Research (60\% Projects 2015-2017 to A.F. and E.O.), and by Fondazione CRT 2017 (Torino, Italy) to E.O.

9. Conflict of interest: The authors declare that they have no competing interests

\begin{abstract}
Abbreviations
BST1, bone marrow stromal cell antigen 1; GPI, glycosylphosphatidylinositol; ARC, ADP-ribosyl cyclase; MPM, malignant pleural mesothelioma; mAb, monoclonal antibody; ECM, extracellular matrix; MSC, mesenchymal stem cells; SCRG1, scrapie responsive gene 1; BM, bone marrow; RA, rheumatoid arthritis; AML, acute myeloid leukemia; ADCC, antibody-dependent cell cytotoxicity; BMSC, bone marrow stromal cell; AraC, cytosine arabinoside; CART cells, chimeric antigen receptor-engineered $\mathrm{T}$ cells.
\end{abstract}

\title{
10. References
}

[1] R.F. Todd, 3rd, J.A. Roach, M.A. Arnaout, The modulated expression of Mo5, a human myelomonocytic plasma membrane antigen, Blood 65(4) (1985) 964-973.

[2] H. Acloque, M.S. Adams, K. Fishwick, M. Bronner-Fraser, M.A. Nieto, Epithelial-mesenchymal transitions: the importance of changing cell state in development and disease, J. Clin. Invest. 119(6) (2009) 1438-1449.

[3] T. Kaisho, J. Ishikawa, K. Oritani, J. Inazawa, H. Tomizawa, O. Muraoka, T. Ochi, T. Hirano, BST-1, a surface molecule of bone marrow stromal cell lines that facilitates pre-B-cell growth, Proc. Natl. Acad. Sci. USA 91(12) (1994) 5325-5329. 
[4] E. Ferrero, F. Malavasi, Human CD38, a leukocyte receptor and ectoenzyme, is a member of a novel eukaryotic gene family of nicotinamide adenine dinucleotide+-converting enzymes: extensive structural homology with the genes for murine bone marrow stromal cell antigen 1 and aplysian ADPribosyl cyclase, J Immunol 159(8) (1997) 3858-3865.

[5] E. Ferrero, F. Saccucci, F. Malavasi, The human CD38 gene: polymorphism, CpG island, and linkage to the CD157 (BST-1) gene, Immunogenetics 49(7-8) (1999) 597-604.

[6] E. Ferrero, N. Lo Buono, S. Morone, R. Parrotta, C. Mancini, A. Brusco, A. Giacomino, S. Augeri, A. Rosal-Vela, S. Garcia-Rodriguez, M. Zubiaur, J. Sancho, A. Fiorio Pla, A. Funaro, Human canonical CD157/Bst1 is an alternatively spliced isoform masking a previously unidentified primatespecific exon included in a novel transcript, Sci. Rep. 7(1) (2017) 15923.

[7] W. Satake, Y. Nakabayashi, I. Mizuta, Y. Hirota, C. Ito, M. Kubo, T. Kawaguchi, T. Tsunoda, M. Watanabe, A. Takeda, H. Tomiyama, K. Nakashima, K. Hasegawa, F. Obata, T. Yoshikawa, H. Kawakami, S. Sakoda, M. Yamamoto, N. Hattori, M. Murata, Y. Nakamura, T. Toda, Genome-wide association study identifies common variants at four loci as genetic risk factors for Parkinson's disease, Nature genetics 41(12) (2009) 1303-1307.

[8] L.H. Zhu, X.G. Luo, Y.S. Zhou, F.R. Li, Y.C. Yang, Y. Ren, H. Pang, Lack of association between three single nucleotide polymorphisms in the PARK9, PARK15, and BST1 genes and Parkinson's disease in the northern Han Chinese population, Chin. Med. J. 125(4) (2012) 588-592.

[9] M. Saad, S. Lesage, A. Saint-Pierre, J.C. Corvol, D. Zelenika, J.C. Lambert, M. Vidailhet, G.D. Mellick, E. Lohmann, F. Durif, P. Pollak, P. Damier, F. Tison, P.A. Silburn, C. Tzourio, S. Forlani, M.A. Loriot, M. Giroud, C. Helmer, F. Portet, P. Amouyel, M. Lathrop, A. Elbaz, A. Durr, M. Martinez, A. Brice, G. French Parkinson's Disease Genetics Study, Genome-wide association study confirms BST1 and suggests a locus on 12q24 as the risk loci for Parkinson's disease in the European population, Hum. Mol. Gen. 20(3) (2011) 615-627.

[10] J. Simon-Sanchez, C. Schulte, J.M. Bras, M. Sharma, J.R. Gibbs, D. Berg, C. Paisan-Ruiz, P. Lichtner, S.W. Scholz, D.G. Hernandez, R. Kruger, M. Federoff, C. Klein, A. Goate, J. Perlmutter, 
M. Bonin, M.A. Nalls, T. Illig, C. Gieger, H. Houlden, M. Steffens, M.S. Okun, B.A. Racette, M.R. Cookson, K.D. Foote, H.H. Fernandez, B.J. Traynor, S. Schreiber, S. Arepalli, R. Zonozi, K. Gwinn, M. van der Brug, G. Lopez, S.J. Chanock, A. Schatzkin, Y. Park, A. Hollenbeck, J. Gao, X. Huang, N.W. Wood, D. Lorenz, G. Deuschl, H. Chen, O. Riess, J.A. Hardy, A.B. Singleton, T. Gasser, Genome-wide association study reveals genetic risk underlying Parkinson's disease, Nature genetics 41(12) (2009) 1308-1312.

[11] S. Yokoyama, N. Al Mahmuda, T. Munesue, K. Hayashi, K. Yagi, M. Yamagishi, H. Higashida, Association Study between the CD157/BST1 Gene and Autism Spectrum Disorders in a Japanese Population, Brain Sci. 5(2) (2015) 188-200.

[12] W. Mo, J. Liu, Z. Zhang, H. Yu, A. Yang, F. Qu, P. Hu, Z. Liu, F. Hu, A study of single nucleotide polymorphisms in CD157, AIM2 and JARID2 genes in Han Chinese children with autism spectrum disorder, Nord J. Psychiatry 72(3) (2018) 179-183.

[13] S. Yamamoto-Katayama, A. Sato, M. Ariyoshi, M. Suyama, K. Ishihara, T. Hirano, H. Nakamura, K. Morikawa, H. Jingami, Site-directed removal of N-glycosylation sites in BST1/CD157: effects on molecular and functional heterogeneity, Biochem. J. 357(Pt 2) (2001) 385-392. [14] B.O. Lee, K. Ishihara, K. Denno, Y. Kobune, M. Itoh, O. Muraoka, T. Kaisho, T. Sasaki, T. Ochi, T. Hirano, Elevated levels of the soluble form of bone marrow stromal cell antigen 1 in the sera of patients with severe rheumatoid arthritis, Arthr. \& Rheum. 39(4) (1996) 629-637.

[15] S. Augeri, S. Capano, S. Morone, G. Fissolo, A. Giacomino, S. Peola, Z. Drace, I. Rapa, S. Novello, M. Volante, L. Righi, E. Ferrero, E. Ortolan, A. Funaro, Soluble CD157 in pleural effusions: a complementary tool for the diagnosis of malignant mesothelioma, Oncotarget (2018) in press.

[16] V. Quarona, G. Zaccarello, A. Chillemi, E. Brunetti, V.K. Singh, E. Ferrero, A. Funaro, A.L. Horenstein, F. Malavasi, CD38 and CD157: A long journey from activation markers to multifunctional molecules, Cytometry. Part B, Clinical cytometry 84(4) (2013) 207-217. 
[17] E. Ortolan, E.V. Tibaldi, B. Ferranti, L. Lavagno, G. Garbarino, R. Notaro, L. Luzzatto, F. Malavasi, A. Funaro, CD157 plays a pivotal role in neutrophil transendothelial migration, Blood 108(13) (2006) 4214-4222.

[18] T. Wakabayashi, H. Naito, J.I. Suehiro, Y. Lin, H. Kawaji, T. Iba, T. Kouno, S. Ishikawa-Kato, M. Furuno, K. Takara, F. Muramatsu, J. Weizhen, H. Kidoya, K. Ishihara, Y. Hayashizaki, K. Nishida, M.C. Yoder, N. Takakura, CD157 Marks Tissue-Resident Endothelial Stem Cells with Homeostatic and Regenerative Properties, Cell Stem Cell 22(3) (2018) 384-397 e6.

[19] J.A. Ross, I. Ansell, J.T. Hjelle, J.D. Anderson, M.A. Miller-Hjelle, J.W. Dobbie, Phenotypic mapping of human mesothelial cells, Adv. Perit. Dial. 14 (1998) 25-30.

[20] E. Aomatsu, N. Takahashi, S. Sawada, N. Okubo, T. Hasegawa, M. Taira, H. Miura, A. Ishisaki, N. Chosa, Novel SCRG1/BST1 axis regulates self-renewal, migration, and osteogenic differentiation potential in mesenchymal stem cells, Sci. Rep. 4 (2014) 3652.

[21] P.M. Hernandez-Campo, J. Almeida, M.L. Sanchez, M. Malvezzi, A. Orfao, Normal patterns of expression of glycosylphosphatidylinositol-anchored proteins on different subsets of peripheral blood cells: a frame of reference for the diagnosis of paroxysmal nocturnal hemoglobinuria, Cytometry. Part B, Clin. Cytom. 70(2) (2006) 71-81.

[22] O.H. Yilmaz, P. Katajisto, D.W. Lamming, Y. Gultekin, K.E. Bauer-Rowe, S. Sengupta, K. Birsoy, A. Dursun, V.O. Yilmaz, M. Selig, G.P. Nielsen, M. Mino-Kenudson, L.R. Zukerberg, A.K. Bhan, V. Deshpande, D.M. Sabatini, mTORC1 in the Paneth cell niche couples intestinal stem-cell function to calorie intake, Nature 486(7404) (2012) 490-495.

[23] F. Suenaga, S. Ueha, J. Abe, M. Kosugi-Kanaya, Y. Wang, A. Yokoyama, Y. Shono, F.H. Shand, Y. Morishita, J. Kunisawa, S. Sato, H. Kiyono, K. Matsushima, Loss of lymph node fibroblastic reticular cells and high endothelial cells is associated with humoral immunodeficiency in mouse graftversus-host disease, J. Immunol. 194(1) (2015) 398-406.

[24] F. Wimazal, M. Ghannadan, M.R. Muller, A. End, M. Willheim, P. Meidlinger, G.H. Schernthaner, J.H. Jordan, W. Hagen, H. Agis, W.R. Sperr, K. Czerwenka, K. Lechner, P. Valent, 
Expression of homing receptors and related molecules on human mast cells and basophils: a comparative analysis using multi-color flow cytometry and toluidine blue/immunofluorescence staining techniques, Tissue Antigens 54(5) (1999) 499-507.

[25] K. Ishihara, Y. Kobune, Y. Okuyama, M. Itoh, B.O. Lee, O. Muraoka, T. Hirano, Stage-specific expression of mouse BST-1/BP-3 on the early B and T cell progenitors prior to gene rearrangement of antigen receptor, Int. Immunol. 8(9) (1996) 1395-404.

[26] T.J. Wu, Y.K. Tzeng, W.W. Chang, C.A. Cheng, Y. Kuo, C.H. Chien, H.C. Chang, J. Yu, Tracking the engraftment and regenerative capabilities of transplanted lung stem cells using fluorescent nanodiamonds, Nature Nanotech. 8(9) (2013) 682-689.

[27] K.M. McNagny, R.P. Bucy, M.D. Cooper, Reticular cells in peripheral lymphoid tissues express the phosphatidylinositol-linked BP-3 antigen, Eur. J. Immunol. 21(2) (1991) 509-515.

[28] R.T. Taylor, S.R. Patel, E. Lin, B.R. Butler, J.G. Lake, R.D. Newberry, I.R. Williams, Lymphotoxin-independent expression of TNF-related activation-induced cytokine by stromal cells in cryptopatches, isolated lymphoid follicles, and Peyer's patches, J. Immunol. 178(9) (2007) 56595667.

[29] Y. Kajimoto, J. Miyagawa, K. Ishihara, Y. Okuyama, Y. Fujitani, M. Itoh, H. Yoshida, T. Kaisho, T. Matsuoka, H. Watada, T. Hanafusa, Y. Yamasaki, T. Kamada, Y. Matsuzawa, T. Hirano, Pancreatic islet cells express BST-1, a CD38-like surface molecule having ADP-ribosyl cyclase activity, Biochem. Biophys. Res. Commun. 219(3) (1996) 941-946.

[30] T.L. Thai, W.J. Arendshorst, Mice lacking the ADP ribosyl cyclase CD38 exhibit attenuated renal vasoconstriction to angiotensin II, endothelin-1, and norepinephrine, Am. J. Physiol. Renal Physiol. 297(1) (2009) F169-176.

[31] A.L. Horenstein, F. Sizzano, R. Lusso, F.G. Besso, E. Ferrero, S. Deaglio, F. Corno, F. Malavasi, CD38 and CD157 ectoenzymes mark cell subsets in the human corneal limbus, Mol. Med. 15(3-4) (2009) 76-84. 
[32] E. Ortolan, R. Arisio, S. Morone, P. Bovino, N. Lo-Buono, G. Nacci, R. Parrotta, D. Katsaros, I. Rapa, G. Migliaretti, E. Ferrero, M. Volante, A. Funaro, Functional Role and Prognostic Significance of CD157 in Ovarian Carcinoma, J. Natl. Cancer Inst. 105(16) (2010) 1160-1177.

[33] E. Ortolan, A. Giacomino, F. Martinetto, S. Morone, N. Lo Buono, E. Ferrero, G. Scagliotti, S. Novello, S. Orecchia, E. Ruffini, I. Rapa, L. Righi, M. Volante, A. Funaro, CD157 enhances malignant pleural mesothelioma aggressiveness and predicts poor clinical outcome, Oncotarget 5(15) (2014) 6191-6205.

[34] S. Yamamoto-Katayama, M. Ariyoshi, K. Ishihara, T. Hirano, H. Jingami, K. Morikawa, Crystallographic studies on human BST-1/CD157 with ADP-ribosyl cyclase and NAD glycohydrolase activities, J. Mol. Biol. 316(3) (2002) 711-723.

[35] Y. Hirata, N. Kimura, K. Sato, Y. Ohsugi, S. Takasawa, H. Okamoto, J. Ishikawa, T. Kaisho, K. Ishihara, T. Hirano, ADP ribosyl cyclase activity of a novel bone marrow stromal cell surface molecule, BST-1, FEBS lett. 356(2-3) (1994) 244-248.

[36] R. Fliegert, A. Gasser, A.H. Guse, Regulation of calcium signalling by adenine-based second messengers, Biochem. Soc. Transact. 35(Pt 1) (2007) 109-114.

[37] M. Podesta, F. Benvenuto, A. Pitto, O. Figari, A. Bacigalupo, S. Bruzzone, L. Guida, L. Franco, L. Paleari, N. Bodrato, C. Usai, A. De Flora, E. Zocchi, Concentrative uptake of cyclic ADP-ribose generated by BST-1+ stroma stimulates proliferation of human hematopoietic progenitors, J. Biol. Chem. 280(7) (2005) 5343-5349.

[38] H. Higashida, M. Liang, T. Yoshihara, S. Akther, A. Fakhrul, C. Stanislav, T.S. Nam, U.H. Kim, S. Kasai, T. Nishimura, N. Al Mahmuda, S. Yokoyama, K. Ishihara, M. Gerasimenko, A. Salmina, J. Zhong, T. Tsuji, C. Tsuji, O. Lopatina, An immunohistochemical, enzymatic, and behavioral study of CD157/BST-1 as a neuroregulator, BMC Neurosci. 18(1) (2017) 35.

[39] Y. Okuyama, K. Ishihara, N. Kimura, Y. Hirata, K. Sato, M. Itoh, L.B. Ok, T. Hirano, Human BST-1 expressed on myeloid cells functions as a receptor molecule, Biochem. Biophys. Res. Commun. 228(3) (1996) 838-845. 
[40] A. Funaro, E. Ortolan, B. Ferranti, L. Gargiulo, R. Notaro, L. Luzzatto, F. Malavasi, CD157 is an important mediator of neutrophil adhesion and migration, Blood 104(13) (2004) 4269-4278.

[41] K. Ishihara, T. Hirano, BST-1/CD157 regulates the humoral immune responses in vivo, Chem. Immunol. 75 (2000) 235-255.

[42] L. Lavagno, E. Ferrero, E. Ortolan, F. Malavasi, A. Funaro, CD157 is part of a supramolecular complex with CD11b/CD18 on the human neutrophil cell surface, J. Biol. Regul. Homeost. Agents 21(1-2) (2007) 5-11.

[43] P. Varshney, V. Yadav, N. Saini, Lipid rafts in immune signalling: current progress and future perspective, Immunology 149(1) (2016) 13-24.

[44] N. Lo Buono, S. Morone, A. Giacomino, R. Parrotta, E. Ferrero, F. Malavasi, E. Ortolan, A. Funaro, CD157 at the intersection between leukocyte trafficking and epithelial ovarian cancer invasion, Front. Biosci. (Landmark Ed) 19 (2014) 366-378.

[45] N. Lo Buono, R. Parrotta, S. Morone, P. Bovino, G. Nacci, E. Ortolan, A.L. Horenstein, A. Inzhutova, E. Ferrero, A. Funaro, The CD157-integrin partnership controls transendothelial migration and adhesion of human monocytes, J. Biol. Chem. 286(21) (2011) 18681-18691.

[46] S. Morone, S. Augeri, M. Cuccioloni, M. Mozzicafreddo, M. Angeletti, N. Lo Buono, A. Giacomino, E. Ortolan, A. Funaro, Binding of CD157 protein to fibronectin regulates cell adhesion and spreading, J. Biol. Chem. 289(22) (2014) 15588-15601.

[47] S. Morone, N. Lo Buono, R. Parrotta, A. Giacomino, G. Nacci, A. Brusco, A. Larionov, A. Ostano, M. Mello-Grand, G. Chiorino, E. Ortolan, A. Funaro, Overexpression of CD157 contributes to epithelial ovarian cancer progression by promoting mesenchymal differentiation., PloS One 7(8) (2012) e43649.

[48] A.P. Vicari, A.G. Bean, A. Zlotnik, A role for BP-3/BST-1 antigen in early T cell development, Int. Immunol. 8(2) (1996) 183-191. 
[49] K.M. McNagny, P.A. Cazenave, M.D. Cooper, BP-3 alloantigen. A cell surface glycoprotein that marks early B lineage cells and mature myeloid lineage cells in mice, J. Immunol. 141(8) (1988) 2551-2556.

[50] A. Schebesta, S. McManus, G. Salvagiotto, A. Delogu, G.A. Busslinger, M. Busslinger, Transcription factor Pax 5 activates the chromatin of key genes involved in B cell signaling, adhesion, migration, and immune function, Immunity 27(1) (2007) 49-63.

[51] M. Itoh, K. Ishihara, T. Hiroi, B.O. Lee, H. Maeda, H. Iijima, M. Yanagita, H. Kiyono, T. Hirano, Deletion of bone marrow stromal cell antigen-1 (CD157) gene impaired systemic thymus independent-2 antigen-induced IgG3 and mucosal TD antigen-elicited IgA responses, J. Immunol. 161(8) (1998) 3974-3983.

[52] D.R. Sutherland, E. Acton, M. Keeney, B.H. Davis, A. Illingworth, Use of CD157 in FLAERbased assays for high-sensitivity PNH granulocyte and PNH monocyte detection, Cytometry. Part B, Clin. Cytom. 86(1) (2014) 44-55.

[53] Y. Shimaoka, J.F. Attrep, T. Hirano, K. Ishihara, R. Suzuki, T. Toyosaki, T. Ochi, P.E. Lipsky, Nurse-like cells from bone marrow and synovium of patients with rheumatoid arthritis promote survival and enhance function of human B cells, J. Clin. Invest. 102(3) (1998) 606-618.

[54] T. Kaisho, K. Oritani, J. Ishikawa, M. Tanabe, O. Muraoka, T. Ochi, T. Hirano, Human bone marrow stromal cell lines from myeloma and rheumatoid arthritis that can support murine pre-B cell growth, J. Immunol .149(12) (1992) 4088-4095.

[55] P. Mirkowska, A. Hofmann, L. Sedek, L. Slamova, E. Mejstrikova, T. Szczepanski, M. Schmitz, G. Cario, M. Stanulla, M. Schrappe, V.H. van der Velden, B.C. Bornhauser, B. Wollscheid, J.P. Bourquin, Leukemia surfaceome analysis reveals new disease-associated features, Blood 121(25) (2013) e149-159.

[56] X. Yang, J. Wang, Precision therapy for acute myeloid leukemia, J. Hematol. Oncol. 11(1) (2018) 3. 
[57] R. Assi, H. Kantarjian, F. Ravandi, N. Daver, Immune therapies in acute myeloid leukemia: a focus on monoclonal antibodies and immune checkpoint inhibitors, Curr. Opin. Hematol. 25(2) (2018) 136-145.

[58] S.C. Goldstein, R.F. Todd, 3rd, Structural and biosynthetic features of the Mo5 human myeloid differentiation antigen, Tissue Antigens 41(4) (1993) 214-218.

[59] C. Krupka, F.S. Lichtenegger, T. Kohnke, J. Bogeholz, V. Bucklein, M. Roiss, T. Altmann, T.U. Do, R. Dusek, K. Wilson, A. Bisht, J. Terrett, D. Aud, E. Pombo-Villar, C. Rohlff, W. Hiddemann, M. Subklewe, Targeting CD157 in AML using a novel, Fc-engineered antibody construct, Oncotarget $8(22)(2017) 35707-35717$.

[60] G. Ghiaur, M. Wroblewski, S. Loges, Acute Myelogenous Leukemia and its Microenvironment: A Molecular Conversation, Semin. Hematol. 52(3) (2015) 200-206.

[61] C. Le Page, J. Sanceau, J.C. Drapier, J. Wietzerbin, Inhibitors of ADP-ribosylation impair inducible nitric oxide synthase gene transcription through inhibition of NF kappa B activation, Biochem. Biophys. Res. Commun. 243(2) (1998) 451-457.

[62] H. Hamidi, M. Pietila, J. Ivaska, The complexity of integrins in cancer and new scopes for therapeutic targeting, British J. Cancer 115(9) (2016) 1017-1023. 


\begin{tabular}{|c|c|c|}
\hline \multicolumn{3}{|c|}{ CD157 expression in healthy tissues } \\
\hline Tissues & Cells & Ref. \\
\hline \multicolumn{3}{|l|}{ Lymphoid } \\
\hline \multirow[t]{5}{*}{ Blood } & Neutrophils & [40] \\
\hline & Basophils & [1] \\
\hline & Monocytes & [1] \\
\hline & Macrophages & [39] \\
\hline & Plasmocytoid dendritic cells & [21] \\
\hline \multirow[t]{3}{*}{ Bone marrow } & B cell precursors & [25] \\
\hline & Myeloid precursors & [1] \\
\hline & Mesenchymal stromal cells & [3] \\
\hline Lymph node & Follicular dendritic cells & [16] \\
\hline Spleen & Fibroblastic reticular cells (mouse) & [23] \\
\hline \multicolumn{3}{|l|}{ Non-lymphoid } \\
\hline \multirow{3}{*}{ Blood vessels } & Endothelial cells & [17] \\
\hline & Tissue-resident vascular endothelial stem cells (mouse) & [18] \\
\hline & Mast cells & [24] \\
\hline Liver & Fetal B cell progenitors (mouse) & [25] \\
\hline Lung & Stem cells (mouse) & [26] \\
\hline \multirow[t]{3}{*}{ Gut } & Brush border, epithelial cells of villi (rat) & [27] \\
\hline & Paneth cells & [22] \\
\hline & $\begin{array}{l}\text { Stromal cells in cryptopatches and lymphoid follicles and Peyer's } \\
\text { patches (mouse) }\end{array}$ & [28] \\
\hline Brain & Amygdala, somatosensory cortex (mouse) & [38] \\
\hline Peritoneum & Mesothelial cells & [19] \\
\hline Pancreas & $\alpha$ and $\beta$-cells & [29] \\
\hline Kidney & Collecting tubuli (mouse) & [30] \\
\hline Eye & Corneal limbal cells, corneal stem cells & [31] \\
\hline \multicolumn{3}{|c|}{ CD157 expression in disease conditions } \\
\hline \multirow[t]{2}{*}{ Blood malignancies } & Acute myeloid leukemia & [59] \\
\hline & B-cell precursor acute lymphoblastic leukemia & [55] \\
\hline Autoimmune diseases & Nurse-like synovial cells in rheumatoid arthritis & [53] \\
\hline Ovarian cancer & Epithelial ovarian cancer cells & [32] \\
\hline Mesothelioma & Epithelioid, biphasic and sarcomatoid pleural mesothelioma & [33] \\
\hline
\end{tabular}

Table 1. Expression of CD157 in lymphoid and non-lymphoid tissues, in normal and pathological conditions. 


\section{Figure legends}

Figure 1. Schematic representation of CD157-mediated intracellular signals. Binding of CD157 to fibronectin is instrumental to form a multimolecular complex with integrins and to promote the assembly of a network of interconnected intracellular signals leading to optimal cell adhesion, migration and survival (red arrows) and counteracting cell apoptosis (blue arrows).

Figure 2. Implication of CD157 in the protective effect of bone marrow microenvironment on AML cells. AML cells interact with bone marrow stromal cells (BMSC) and extracellular matrix proteins (such as, fibronectin) via adhesion molecules. CD157 expressed by AML cells and BMSC bind to the heparin binding domain (in red) of selected extracellular matrix components secreted both by tumour cells and stromal cells. Cell-cell interaction is potentiated by integrins, which bind both ECM proteins (at their cell binding domain, in yellow) and membrane receptors expressed by BMSC, such as vascular cell adhesion protein 1 (VCAM-1). These interactions between AML cells and BMSC trigger intracellular signals which protect tumor cells from apoptosis, promote cell survival, and eventually confer drug resistance to the tumor. Therapeutic strategies that target these interactions would reduce the emergence of acquired resistance. 


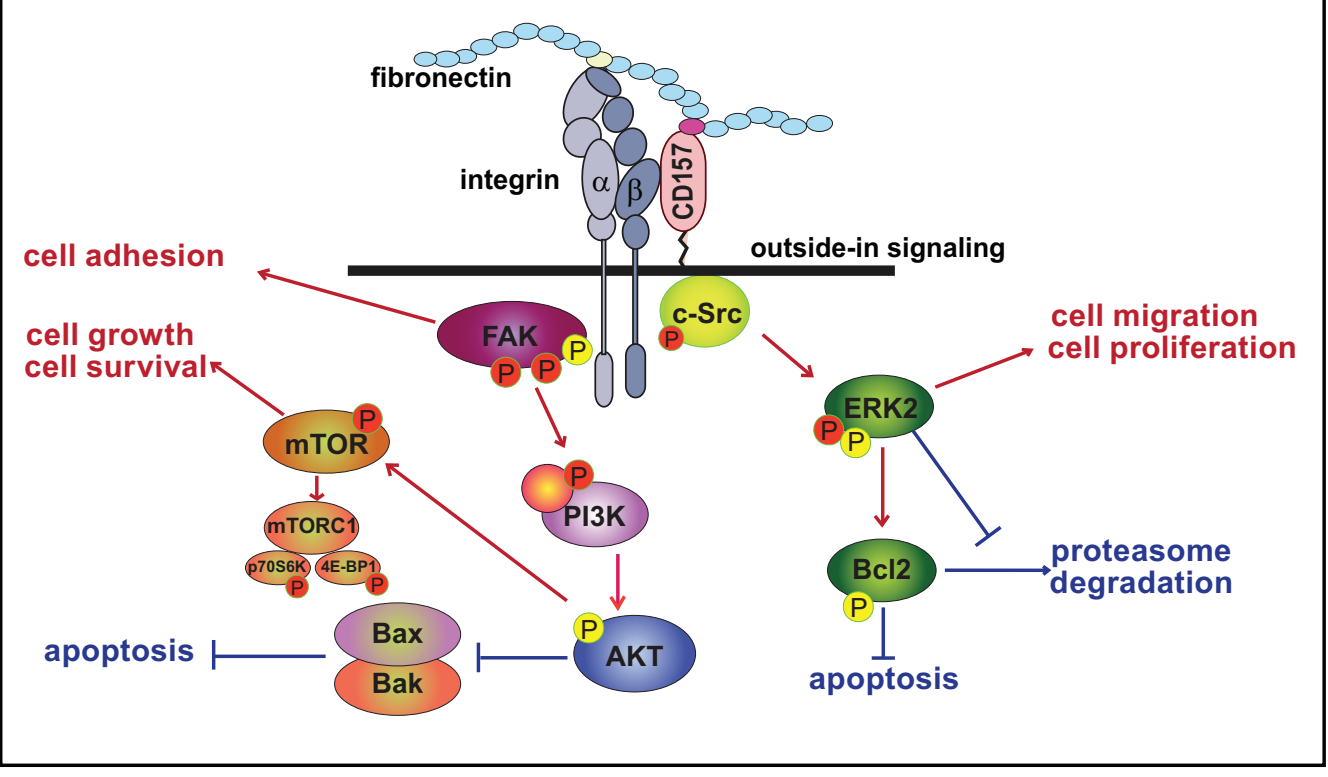




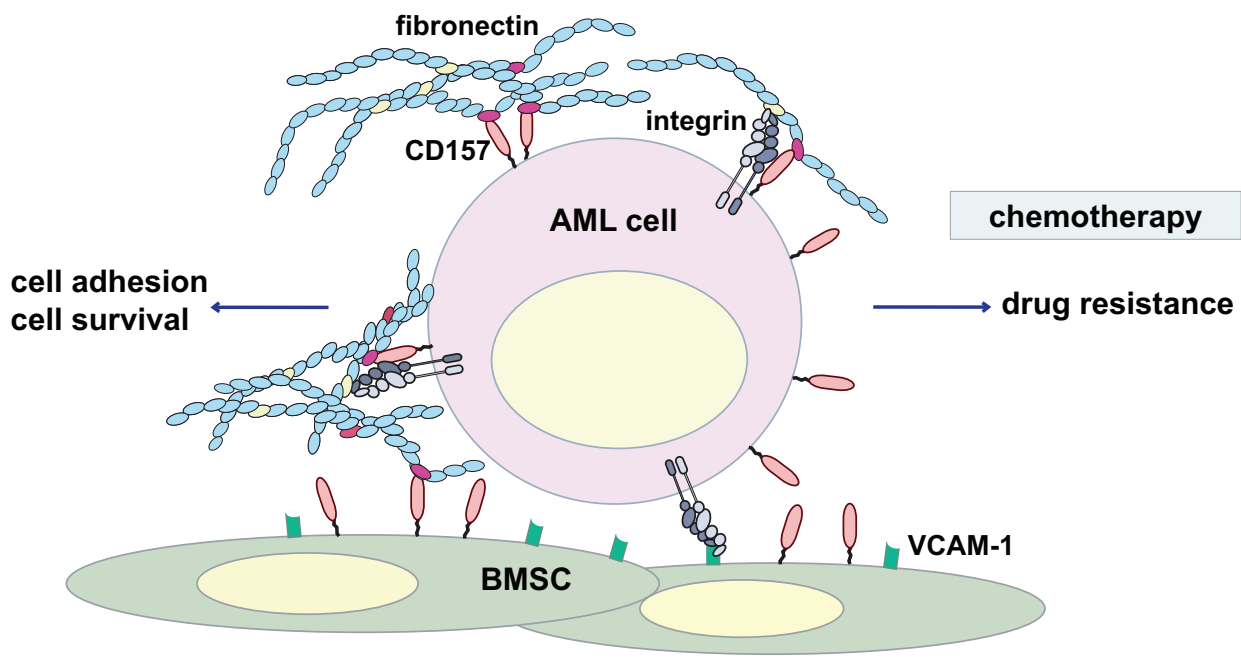

Figure 2 